\title{
Physical activity and absenteeism for worker's disease: a systematic review
}

\author{
Michell Vetoraci Viana',2, Almir de França Ferraz1, Tiago Costa de Figueiredo², Roberta Luksevicius Rica1, \\ Luciane Bresciani Salaroli ${ }^{3}$, Danilo Sales Bocalini ${ }^{4}$, Maria Luiza de Jesus Miranda', Aylton Figueira Júnior ${ }^{1}$
}

\begin{abstract}
Introduction: Although Brazil has complete legislation that establishes guidelines and recommendations for companies regarding Occupational Health and Safety, according to data from the Ministry of Labor and Social Security, indices of absenteeism and absences from work functions increase with each year. Objective: To identify the association of the level of physical activity on absenteeism by diseases in workers, through a systematic review. Methods: Four databases (Lilacs, SciELO, Medline via Pubmed and Cochrane Library) were consulted from November 10 to 23, 2017. Results: The selection process of the articles were included after screening 25 articles: (08) articles did not mention workers, only school children, (05) articles were systematically reviewed, and (12) articles had randomized clinical trials. The systematic relationship included a bias analysis, data extraction and important discussions of the characteristics of the articles selected so that we had breadth of knowledge produced in this theme. Conclusion: We evidenced the need for more research in the area of physical activity and less number of absenteeism due to diseases in workers.
\end{abstract}

Keywords: Physical Activity; Workplace; Absenteeism; Occupational Disease.

\section{INTRODUCTION}

The rate of absenteeism is an important indicator used to measure conditions and quality of life at work. The economic losses caused to companies and social security due to absences and withdrawals from work are significant. Therefore, investment in employee health issues must be observed and dealt with responsibly, as it has a significant impact on payroll costs and influences productivity. It is necessary to be part of the routine of companies, actions that promote health, quality of life and safety at work ${ }^{(1)}$. Although Brazil has a complete legislation that establishes guidelines and recommendations for companies regarding Occupational Health and Safety issues, according to data from the Ministry of Labor and Social Security, indices of absenteeism and absences from work functions increase every year ${ }^{(2)}$.

Once exposed to this scenario, the practice of physical activity, understood as any body movement produced by skeletal muscles those results in energy expenditure above resting levels is an important non-pharmacological tool for improving health conditions. The behavior toward a more physically active life includes occupational, daily life, displacement and leisure activities ${ }^{(3,4)}$. According to a literature review on physical activity and health conducted by the US Department of Health and Human Services - USDHHS, there is scientific evidence of moderate strength that demonstrates that physical activity helps maintain weight loss, improves sleep, and reduces risk of hip fracture and osteoporosis. In addition, strong evidence indicates that physical activity reduces the risk of premature death, coronary heart disease, stroke, high blood pressure, type 2 diabetes, breast and colon cancer, excessive weight gain, falls, depression, and loss of cognitive function ${ }^{(5)}$. On the other hand, some risk factors and occupational characteristics may contribute to the development of chronic health risks, such as type 2 diabetes, adiposity, length of service, sleep disorder, stress, physical inactivity, inadequate diet, socio-cultural and occupational conditions unfavorable to a healthy lifestyle ${ }^{(6-7)}$.

In Brazil, if physical inactivity were eliminated, approximately $3 \%$ of chronic diseases, $4 \%$ of cases of type 2 diabetes, around $2.5 \%$ of cases of breast cancer and $6 \%$ of cases of colonous cancer would be avoided ${ }^{(8)}$. Based on the previous assertion, a survey of 1236 workers (age $=43 \pm 9.8$ years) found that there was a significant difference $(p=0.03)$ in the mean number of days of separation between cyclists ( 7.4 days) and non-cyclists (8.7 days). This result therefore not only contributes to employee health, but reducing absenteeism can also result in a financial benefit to the employer ${ }^{(9)}$.

In the work of Lahti et al. ${ }^{(10)}$, with inactive women and men, workers in a company who started a vigorous physical activity

Corresponding Author: Michell Vetoraci Viana, Adress: Av. Carlos Eduardo Monteiro de Lemos, 337. Vitória (ES), Brazil, Zip Code: 29060-120. E-mail: michell@oikossaude.com.br ${ }^{1}$ Departamento de Pós-Graduação em Educação Física, Universidade São Judas Tadeu, São Paulo, SP, Brasil.

Full list of author information is available at the end of the article.

Financial support: Nothing to declare

Submission date 10 August 2018; Acceptance date 22 September 2018; Publication date 17 October 2018 
program had a significantly lower risk of self-certification $(\mathrm{RR}=0.80,95 \% \mathrm{Cl} 0,(\mathrm{RR}=0.63,95 \% \mathrm{Cl} 0.49-, 83)$ with a lower risk of sick leave. These data support the continuity of the current study in the adoption of a physical activity program in order to evaluate not only the variables already suggested, but also the control of drug reduction. For the author's knowledge and after a review of the literature, no systematic review studies were written in Portuguese, dealing with the relationship between physical activity level and absenteeism indexes. This study becomes relevant, as it directly influences the actions related to the implementation of physical activity programs in companies, highlighting the relation of the level of activity with absenteeism in the work environment. Thus, the objective of this systematic review was to verify the practice of physical activity on absenteeism indices in workers. The hypothesis of this study is that there is an inverse relationship between the level of physical activity and the rates of absenteeism.

\section{METHODS}

\section{Literature search}

Four databases (Lilacs, SciELO, Medline via Pubmed and Cochrane Library) were consulted between November 10 and 23, 2017. The descriptors and respective Medical Subject Headings (MeSH) terms used were: physical activity, workplace and absenteeism. Articles in English, Spanish and Portuguese published between 1953 and 2017 were evaluated, and included observational studies that studied workers, whose outcome was absenteeism, diagnosed by internationally used criteria. Randomized and interventional trials were excluded. The research was carried out through the systematic review of literature that sought to analyze and systematically review the association of the level of physical activity on absenteeism in workers. Thus, the detail of the review was based on the universe of analysis.

The review research was performed by phases that demonstrate the identification of the selection process of the articles. In the first phase, searches were carried out in the electronic index databases of PubMed, MEDLINE, LILACS and SciELO, in the period of January 1990, November 2017 and list of referenced articles identified. The selection of the keywords was used in the selection process review to the Descriptors in Health Sciences (DeCS). The selection was obtained by the insertion of the descriptors through advanced search and union of search terms, and in PubMed it has the denomination of "Mesh". The terms descriptors used were: "Physical Activity", "workplace" and "absenteeism". Within this process we used cognitive logical operators for the terms "AND" and "OR" for the effective tracking of the publications in the bases: PubMed, MEDLINE and LILACS searches through "Mesh" composing several sums of terms for detailing the systematic search according to the following term: Search
(((Workplace [Mesh] OR “Workplaces" OR "Work Location" OR "Location, Work" OR "Locations, Work" OR "Work Locations" OR "Work-Site" OR "Work Site" OR "Work-Sites" OR "Work Place" OR "Place, Work" OR "Places, Work" OR "Work Places" OR "Job Site" OR "Job Sites" OR "Site, Job" OR "Sites, Job" OR "Worksite" OR "Worksites")) AND (Physical activity [Mesh] OR "Exercises" OR "Physical Activity" OR "Activities, Physical" OR "Activity, Physical" OR "Physical Activities" OR "Exercise, Physical" OR "Exercises, Physical" OR "Physical Exercise" OR "Physical Exercises" OR "Acute Exercise" OR "Acute Exercises" OR "Exercise, Acute" OR "Exercises, Acute" OR "Exercise, Isometric" OR "Exercises, Isometric" OR "Isometric Exercises" OR "Isometric Exercise" OR "Exercise, Aerobic" OR "Aerobic Exercise" OR "Aerobic Exercises" OR "Exercises, Aerobic" $O R$ "Exercise Training" OR "Exercise Trainings" OR "Training, Exercise" OR "Trainings, Exercise")) AND absenteeism. In the first analysis, 136 articles related to the themes were obtained. In the SciELO database, the advanced search was performed with the same terms referenced in the systematic review, and three scientific articles were identified. Overall, 139 articles were selected in the review.

In the second phase, the selection of articles by two researchers was carried out by means of readings of the titles of the articles to verify the adequacy to the theme of the review. When the decision could not be taken only by the titles, we resorted to another more specific topic through the summary check. While remaining indecisive, the whole article had to be read, which continued in the same total amount. In the third phase, the exclusion and inclusion criteria were applied. The following criteria were considered in the exclusion process: articles not related to physical activity and absenteeism. In the inclusion process it included the following criteria: a sample of workers, observational studies. After this analysis filter, there were 25 publications, the remainder contemplating schoolchildren, systematic review, randomized clinical studies. The systematic relationship includes a bias analysis, data extraction and important discussions of the characteristics of the selected articles in order to have an amplitude of the knowledge produced in this theme ${ }^{(11)}$, according Figure 1.

\section{RESULTS}

Of the 139 eligible studies in the first selection phase, after applying the inclusion and exclusion criteria, only 5 were selected, where the main information is shown in Table 1 , with absenteeism and the various independent variables as Physical Activity and Metabolic Risk ${ }^{(12)}$, volume and intensity of the exercise ${ }^{(13)}$, Behavior, health perception and work characteristic ${ }^{(14)}$, Physical Activity and cardiorespiratory fitness $^{(15)}$ and Exercise reported ${ }^{(16)}$. The articles used different methods to determine the practice of physical activity and factors that influence absenteeism at work as showed at Table 2. 


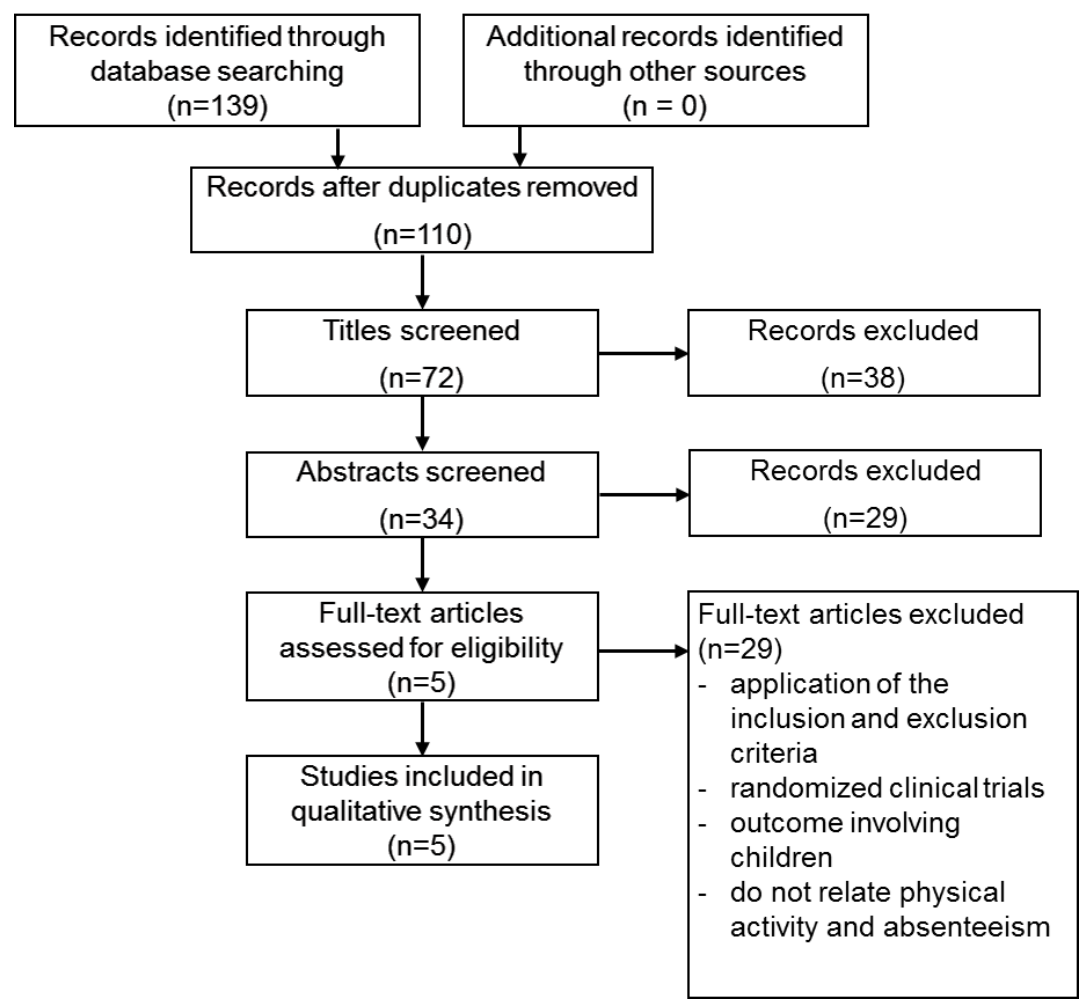

Figure 1. Flowchart for selection of research articles.

Regarding bias risk analysis, the instrument used for analysis was "Cochrane risk of bias tool"(17), which assesses the risk of bias in observational studies through the following items: confounding, selecting the participants, assessing the intervention, not receiving the assigned intervention, losses, measurement of outcomes and selective reporting of outcomes.

\section{DISCUSSION}

Taking into account the specific approach in workers, it was found that, for the most part, these professionals are at risk of health. Within this quantitative, the metabolic syndrome ${ }^{(12)}$, body mass index ${ }^{(13)}$, motivational models ${ }^{(14)}$, gender ${ }^{(15)}$, the frequency of physical activity ${ }^{(16)}$, has a significant contribution of this phenomenon in the development of cardiometabolic diseases interfering with physical, health and occupational conditions $^{(18)}$.

This systematic review found associations between physical activity and health variables that impact both the worker's performance and the risk factors of illness in and out of work. Research indicates that physical activity is one of the factors contributing to the maintenance of good health, absence in the workplace and the appearance ${ }^{(19,20)}$, as well as the elaboration of awareness programs and incentive to practice physical exercises and their relation with the reduction of absenteeism ${ }^{(21)}$. Although a large part of the $\operatorname{articles}^{(12-14)}$ included in the study report that the best strategy is the regular practice of physical activity, suitability for healthy lifestyle and prevention of diseases. The results clearly show that workers are exposed to conditions that impair their health, such as stress, metabolic syndrome, sedentary lifestyle, and lack of awareness of healthy life $\mathrm{e}^{(15,16,22)}$.

Despite warnings about the potentially negative health consequences of a sedentary lifestyle, a large number of employed adults are not physically active enough. Promoting the practice of physical activity in normal daily routines is a promising way to reach a large number of less active people, such as commuting.

Hendrisken et al. ${ }^{(9)}$, in a study of 1236 workers aged 40 to 50 years, showed that cycling workers had a lower frequency of work leave when compared to those who did not practice cycling, revealing a mean duration of days of cyclists (7.4 days) and non-cyclists (8.7 days). Another important information is that it does not only contribute to employee health but to reduce absenteeism resulting in financial benefit to the employer. These findings are similar to those found in the studies of Viana et al. ${ }^{(23)}$ Koenders et al. ${ }^{(24)}$ and Saelensminde et al. ${ }^{(25)}$, although they do not corroborate with the findings, which did not present a significant difference between the time of withdrawal between the different levels of physical activity. This is probably due to the fact that the company does not have a closed program about the regular and controlled practice of physical exercise. These findings support previous findings that vigorous physical activity ${ }^{(13,25)}$ 
Table 1. Main methodological characteristics and results of systematic review studies involving physical activity and health with their effects on absenteeism indexes at work.

\begin{tabular}{|c|c|c|c|c|}
\hline Authors & Goal & Methods & $\begin{array}{l}\text { Protocol } \\
\text { Outcome }\end{array}$ & Result/Conclusion \\
\hline Burton et al., 2014 & $\begin{array}{l}\text { Examine the self-reported } \\
\text { physical activity of } \\
\text { employees and risk of } \\
\text { metabolic syndrome } \\
\text { and its association with } \\
\text { health, absenteeism and } \\
\text { presenteeism. }\end{array}$ & $\begin{array}{l}\text { They carried out inventories } \\
\text { through questionnaires to } \\
\text { verify the level of physical } \\
\text { activity, after } 1 \text { month } \\
\text { physical fitness tests. } \\
\text { Application of the } \\
\text { Questionnaire (WLQ), Lerner } \\
\text { et al, } 2001 \text {. }\end{array}$ & $\begin{array}{l}\text { AHA / NHLBI8 Criteria for } \\
\text { MetS, eight item work } \\
\text { restriction } \\
\text { Questionnaire (WLQ) risk } \\
\text { assessment for health and } \\
\text { physical. }\end{array}$ & $\begin{array}{l}\text { Employees without Metabolic } \\
\text { Syndrome (MetS) and sufficiently } \\
\text { and physically active have attained } \\
\text { than those with MetS who are } \\
\text { insufficiently active or inactive. } \\
\text { Health care and operating costs are } \\
\text { higher for employees with MetS. } \\
\text { Absenteeism and presenteeism } \\
\text { were also significantly lower for } \\
\text { employees achieving sufficient } \\
\text { physical activity. All risk factors for } \\
\text { MetS were mitigated for regular } \\
\text { practitioners. Employers should } \\
\text { consider programs and services to } \\
\text { support regular aerobic exercise to } \\
\text { address the increasing prevalence } \\
\text { and costs of MetS in the workforce. }\end{array}$ \\
\hline
\end{tabular}

The volume of physical activity was weak and somewhat inconsistently associated with absence of disease.

Examining the volume and intensity of PA is associated with lower (14 days) and longer (414 days) absence of disease over

Lahti et al, 2010 the next 3.9 years. And if these associations can be explained by lower socioeconomic positions (SEP), body mass indexes (BMI) and physical health functioning.
The average weekly physical activity level was surveyed and the average expenditure was estimated. Total physical activity was converted to metabolic equivalent index (MET). (1) Inactive, (2) Moderate active, (3) Active vigorously, (4) Very active moderately, (5) very active vigorously, and (6)) Packaging.
Questionnaires about physical activity during leisure or displacement within 12 months. Researchers in 2000-2002, employees of 40-60 year-old Helsinki City $(n=56465,79 \%$ female). However, men and women who were vigorously active systematically reduced the risk of absence of disease, whereas the same volume of moderately intensive physical resources did not reduce the risk of absence of disease. Adjusting for BMI and, in particular, the functioning of physical health attenuated these associations, after which associations lost statistical significance. The results suggest that vigorous. Physical activity is associated with absence of disease and may contribute to a better work capacity.

Imbalance, effort-reward, lack of support from supervisors or co-workers, negative affectivity, exhaustion, and impaired health

To evaluate the relationship of behavior and health perception,

Hanebuth et al, 2006 work characteristics, and demographic variables with absenteeism due to illness in industry employees.
Predictors and possible confounders were regressed against frequency indices and the time lost index derived from the day-to-day absence data of 1524 employees at a factory in Germany. Frequency rates were the number of sick leave within 1 year. (smoking, physical activity, alcohol intake, age, gender, body mass index, income) were regressed against frequency indexes and the lost time index derived. perception were,

Significantly, it is associated with signs of absence and index of lost time. Work requirements and control of work, as well as excess commission, were not related to absenteeism rates. Multivariate models suggest mediation through reduction of health-related quality of life. cardiovascular diseases. higher absenteeism rates than for male officers were related to decreased absenteeism
Medical examination, Health risk assessment and physical fitness cooper jog (cardiovascular, body composition, muscle

Sedentary police and women have active and male agents, respectively. Physical or female aptitude was

not related to the decrease of obtained strength and endurance, and flexibility) and evaluation of for all officers except those exempted from testing due to injury or illness. for medical care among law enforcement officers $(N=734)$. 
Table 1. Continued...

Authors

Goal
Methods
Protocol

Outcome
Result/Conclusion

In total, 59\% reported that they were not absent from work due to illness during the previous year, $12 \%$ were inexperienced, $14 \%$ reported 1 day a week, $20 \%$ reported 2 days a week, $26 \%$ reported three days per week and $30 \%$ reported having exercised 4 days a week. Regarding the exercise, the results indicated that $34.83 \%$ of the participants involved

Tobacco use, nutrition, exercise, safety, dental To compare the frequency of self-reported exercise participation with annual disease-related absenteeism in a large sample of working
A questionnaire was conducted on the health profile of working adults and physical activity for days and weeks.
Health, self-care, prevention, medical care, men's health, women

health, medical history, alcohol consumption, general well-being (stress) and biometrics measures. Completeness Questionnaire. adults. 2001
Jacobson \& Aldana, in weekly exercise, $23.85 \%$ exercised

1 day per week, $13.56 \%$ exercised

2 days a week, $14.27 \%$ exercised

3 days a week and $13.47 \%$ exercised

4 or more days per week. Regarding

the annual absence related to

the disease, $52.51 \%$ reported

1 to 3 days, $21.59 \% 4$ to 6 days, and $25.94 \%$ to 7 or more days lost. About $14 \%$ of workers reported missing 12 or more days per year. Exercise was associated with lower absenteeism compared to no exercise, and 2 days of exercise was more favorable than one. These data suggest a significant relationship between frequency of exercise and absenteeism related to the disease.

Table 2. Evaluation of methodological quality and risk of bias of studies in observational studies included in the review ${ }^{17}$. Classification of biases: "low" risk, "moderate risk", "severe risk", "critical risk" (when the criteria and requirements of the item are not met) and "no information".

\begin{tabular}{|c|c|c|c|c|c|c|c|}
\hline Author / year & Confusion & $\begin{array}{l}\text { Selection of } \\
\text { participants }\end{array}$ & $\begin{array}{l}\text { Exposure } \\
\text { gauging }\end{array}$ & $\begin{array}{l}\text { Non-receipt } \\
\text { of assigned } \\
\text { exposure }\end{array}$ & Losses & $\begin{array}{c}\text { Benchmarking } \\
\text { on outcomes }\end{array}$ & $\begin{array}{l}\text { Selective } \\
\text { reporting of } \\
\text { outcomes }\end{array}$ \\
\hline Burton et al. ${ }^{14}$ & Low & Low & Low & Low & Low & Low & Low \\
\hline Hanebuth et al. ${ }^{16}$ & Low & Low & Low & Low & Low & Low & Low \\
\hline Steinhardt et al. ${ }^{17}$ & Low & Low & Low & Low & Moderate & Moderate & Low \\
\hline $\begin{array}{c}\text { Jacobson \& } \\
\text { Aldana }^{18}\end{array}$ & Low & Low & Low & Low & Moderate & Low & Low \\
\hline Lahti et al. ${ }^{34}$ & Low & Low & Moderate & Moderate & Moderate & Low & Low \\
\hline
\end{tabular}

and good aerobic fitness ${ }^{(26,27)}$ contribute to the reduction of absenteeism due to illness. However, changes in physical activity and suggested that even small increases in physical activity are beneficial, especially for the physical domain among the SF-36 domains among middle-aged women, and that larger increases lead to greater benefits ${ }^{(28)}$. In addition, increased physical activity during middle age helps reduce health costs ${ }^{29}$ and reduces the risk of premature mortality ${ }^{(30)}$. In this sense, the adoption of physical activity during leisure time is beneficial for health among workers ${ }^{(31)}$, although such benefits vary according to the type of activity developed ${ }^{(32,33)}$.

In the study by Lahti et al. ${ }^{(34)}$, it was found that a company that implemented a vigorous physical activity program, workers achieved a significantly lower rate of self-medication reported, use of proven drugs, and a lower risk of withdrawal due to diseases. These data support the continuity of the current study in the adoption of a physical activity program in order to evaluate not only the variables already suggested, but also the control of drug reduction. We show in this study that, there is a need for further research in the area of physical activity and association with absenteeism in workers.

\section{CONCLUSION}

After analyzing the results, it was found that a cardiometabolic profile, including changes in the practice of regular physical activity, managerial and administrative 
models, work characteristics as well as healthy behavior, is not only a benefit for employees, but is also likely that is beneficial to employers who employ healthy workers, and can minimize the impacts of absenteeism on the company.

\section{AUTHORS CONTRIBUTION}

MVV, AFF and AFJ were the main contributors in the study intellectual concept. MLJM and RLR contributed in literature review and data analyze. TCF, LBS and DSB had active participation on writing and study preparing.

\section{CONFLICT OF INTEREST}

Nothing to declare.

\section{AUTHORS DETAILS}

²Departamento de Educação Física, Universidade Estácio de Sá, Vitoria, ES, Brasil. ${ }^{3}$ Programa de Pós-Graduação em Saúde Publica, Nutrição e Saúde. Departamento de Educação Integrada. Universidade Federal do Espirito Santo, Vitória, ES, Brasil. " Laboratório de Fisiologia e Fisiopatologia Experimental. Centro de Educação Física e Desporto. Universidade Federal do Espírito Santo, Vitória, ES, Brasil.

\section{REFERENCES}

1. Tolbert DV, Mc Collister KE, LeBlancw G, Lee DJ, Fleming LE, Muennig P. The economic burden of disease by industry: Differences in quality-adjusted life years and associated costs. Am J Ind Med. 2014;57(7):757-763.

2. Empresa de Tecnologia e Informações da Previdência Social - DATAPREV. Anuário Estatístico de Acidentes de Trabalho-AEAT. Brasília: Ministério da Previdência Social; 2013.

3. Caspersen CJ, Powell KE, Christenson GM. Physical activity, exercise, and physical fitness: definitions and distinctions for health-related research. Public Health Rep. 1985;100(2): 126-31.

4. Nahas. MV. Atividade Física, saúde e qualidade de vida: conceitos e sugestões para um estilo de vida ativo. $6^{\text {a }}$ ed. Londrina: Midiograf; 2013.

5. U.S. Departamento of Health and Human Services. Physical Activity Guidelines Advisory Committee Report. 2008. Washington: U.S. Departamento f Health and Human Services; 2008.

6. Minayo M.C.S., Souza E.R., Constantino P. Missão prevenir e proteger: condições de vida, trabalho e saúde dos policiais militares do Rio de Janeiro. Rio de Janeiro: Editora Fiocruz; 2008. p. 328.

7. Czaja-Miturai I; Merecz-Kot D.; Szymczk W.; Bortkiewicz A. Cardiovascular risk factors and life and occupational stress among policemen. Med Pr. v. $64, n^{\circ} 3,2013$, p. 335-48.

8. Rezende LF, Rabocow FM, Viscondi JY, Luiz OC, Matsudo VK, Lee IM. Efecct of Physical Inactivity on Major Non-Communicable Diseases and Life Expectancy in Brazil. J Phys Act Health. 2014.

9. Hendriksen IJ, Simons M, Garre FG, Hildebrandt VH. The association between commuter cycling and sickness absence. Preventive medicine. Aug 2010;51(2):132-135.

10. Lahti J, Lahelma E, Rahkonen O. Changes in leisure-time physical activity and subsequent sickness absence: A prospective cohort study among middle-aged employees. Preventive medicine. Dec 2012;55(6):618-622.

11. van Amelsvoort LG, Spigt MG, Swaen GM, Kant I. Leisure time Phsical activity and sickness absenteeism; a prospective study. Occup Med (Lond). 2006;56(3): 210-2.

12. Martinez-López E, Saldarriaga-Franco J. Inactividad Fisica y Ausentismo em el Ámbito Laboral. Revista de Salud Pública. 2008;10:227-38.

13. Strengthening the Reporting of Observacional Studies in Epidemiology (STROBE) 2007.

14. Burton WN, et al., The Association of Self-Reported Employee Physical Activity With Metabolic Syndrome, Health Care Costs, Absenteeism, and Presenteeism 2014.
15. Lahti J, Laaksonen M, Lahelma E, Rahkonen O. The impact of physical activity on sickness absence. Scandinavian journal of medicine \& science in sports. Apr 2010;20(2):191-199.

16. Hanebuth et al., Health-Related Quality of Life, Psychosocial Work Conditions, and Absenteeism in na Industrial Sample of Blue- and WhiteCollar Employees: A Comparison of Potential Predictors, 2006.

17. Steinhardt et al., The Relationship of Physical Activity and Cardiovascular Fitness to Absenteeism and Medical Care Claims Among Law Enforcement Officers, 1991.

18. Jacobson \& Aldana, Relationship Between Frequency of AerobicActivity and IIIness-Related Absenteeism in a Large Employee Sample, 2001.

19. Sterne, Jonathan AC et al. "ROBINS-I: A Tool for Assessing Risk of Bias in Non-Randomised Studies of Interventions." The BMJ 355 (2016): i4919. PMC. Web. 2 Feb. 2018.

20. Czaja-Miturai I; Merecz-Kot D.; Szymczak W.; Bortkiewicz A. Cardiovascular risk factors and life and occupational stress among policemen. Med Pr. v. 64, $n^{\circ} 3,2013$, p. 335-48.

21. Tharkar S, Kumpatla S, Muthukumaran P, Viswanathan V. High prevalence of metabolic syndrome and cardiovascular risk among police personnel compared to general population in India. J Assoc Physicians India. 2008;56:845-849.

22. Farias Júnior, José Cazuza de. (In) Atividade física e comportamento sedentário: estamos caminhando para uma mudança de paradigma? Revista Brasileira de Atividade Física \& Saúde. v 16. N 4. 2011, 279-280.

23. Viana, Michell Vetoraci, C. Samaria, N. Júnior Rudy, V. Danyela, E. Dantas. Effects of a concurrent physical exercise program on aerobic power and body composition in adults. The Journal of Sports Medicine and Physical Fitness. 2014;vol.54, no4:441-446.

24. Koenders PG, van Deursen CGL. Traveling to and for work and sickness absence in the banking sector. TBV. 2008;16:143-148.

25. Saelensminde K. Cost-benefit analyses of walking and cycling track networks taking into account insecurity, health effects and external costs of motorized traffic. Transportation Research part A. 2004;38:593-606.

26. Proper KI, van den Heuvel SG, De Vroome EM, Hildebrandt VH, Van der Beek AJ. Dose-response relation between physical activity and sick leave. British journal of sports medicine. Feb 2006;40(2):173-178.

27. Strijk JE, Proper KI, van Stralen MM, Wijngaard $P$, van Mechelen $W$, van der Beek AJ. The role of work ability in the relationship between aerobic capacity and sick leave: a mediation analysis. Occupational and environmental medicine. Oct 2011;68(10):753-758.

28. Kyrolainen $\mathrm{H}$, Hakkinen $\mathrm{K}$, Kautiainen $\mathrm{H}$, Santtila M, Pihlainen $\mathrm{K}$, Hakkinen A. Physical fitness, BMI and sickness absence in male military personnel. Occup Med (Lond). Jun 2008;58(4):251-256.

29. Wolin KY, Glynn RJ, Colditz GA, Lee IM, Kawachi I. Long-term physical activity patterns and health-related quality of life in U.S. women. American journal of preventive medicine. Jun 2007;32(6):490-499.

30. Martinson BC, Crain AL, Pronk NP, O’Connor PJ, Maciosek MV. Changes in physical activity and short-term changes in health care charges: a prospective cohort study of older adults. Preventive medicine. Oct 2003;37(4):319-326.

31. Byberg L, Melhus H, Gedeborg R, et al. Total mortality after changes in leisure time physical activity in 50 year old men: 35 year follow-up of population based cohort. British journal of sports medicine. Jul 2009;43(7):482.

32. Woodcock J, Franco OH, Orsini N, Roberts I. Non-vigorous physical activity and all-cause mortality: systematic review and meta-analysis of cohort studies. International journal of epidemiology. Feb 2011;40(1):121-138.

33. Holtermann A, Hansen JV, Burr H, Sogaard K, Sjogaard G. The health paradox of occupational and leisure-time physical activity. British journal of sports medicine. Mar 2012;46(4):291-295.

34. Sabia S, Dugravot A, Kivimaki M, Brunner E, Shipley MJ, Singh-Manoux A. Effect of intensity and type of physical activity on mortality: results from the Whitehall II cohort study. American journal of public health. Apr 2012;102(4):698-704. 